Research Article

\title{
The Use of Sugarcane Bagasse to Remove the Organic Dyes from Wastewater
}

\author{
Meryem Kerrou (D, Najia Bouslamti, Abdelaziz Raada, Abdellah Elanssari, Driss Mrani, \\ and My Sliman Slimani
}

University Moulay Ismail of Meknes, Faculty of Sciences and Techniques Errachidia, Department of Chemistry, Laboratory of Chemistry, Environment, and Materials Analysis Team, Meknes, Morocco

Correspondence should be addressed to Meryem Kerrou; kerrou.meryem@gmail.com

Received 2 March 2021; Revised 1 June 2021; Accepted 14 June 2021; Published 29 June 2021

Academic Editor: Valentina Venuti

Copyright (c) 2021 Meryem Kerrou et al. This is an open access article distributed under the Creative Commons Attribution License, which permits unrestricted use, distribution, and reproduction in any medium, provided the original work is properly cited.

In the present study, the potential of sugarcane bagasse (SCB) was evaluated by methylene blue (MB) retention. The selected lowcost adsorbent was characterized by scanning electron microscopy (SEM) coupled with energy-dispersive X-ray spectroscopy (EDX), Fourier transform infrared spectroscopy (FTIR), BET method, and determination of the point of zero charge (pHzpc). Batch kinetic and isothermal studies were performed to examine the effects of contact time, initial dye concentration, adsorbent dose, $\mathrm{pH}$, and temperature. The results show that the kinetic study of $\mathrm{MB}$ adsorption on sugarcane bagasse is very fast; the equilibrium is reached after only 20 minutes. The kinetic model of pseudo-second-order and the Langmuir isotherm model perfectly explain the adsorption process of $\mathrm{MB}$ with a monolayer adsorption capacity equal to $49.261 \mathrm{mg} \cdot \mathrm{g}^{-1}$ activation parameters' values such as free energy $\left(\Delta G^{\circ}\right)$, enthalpy $\left(\Delta H^{\circ}\right)$, and entropy $\left(\Delta S^{\circ}\right)$ also determined as $-4.35 \mathrm{~kJ} \cdot \mathrm{mol}^{-1},-31.062 \mathrm{~kJ} \cdot \mathrm{mol}^{-1}$, and $-0.084 \mathrm{~J} \cdot \mathrm{mol}^{-1} \cdot \mathrm{K}^{-1}$, respectively. Besides, the thermodynamic parameters of the methylene blue sugarcane bagasse system indicate that the exothermic adsorption process is spontaneous.

\section{Introduction}

Industrial wastewater pollution has become a common problem in most countries [1] and one of the biggest environmental problems in recent decades. Industrial discharges include dyes used in different areas such as printing, food, cosmetics, and clinical products, but particularly in the textile industry [2]. The discharge of these colored effluents in nature affects not only humans and water but the whole environment. More than 14 million chemical products can be found in the environment; this number is gradually increasing which poses a negative impact on the biosphere and threats the balance of the natural ecosystem. Indeed, the toxic chemical products dumped into the water are genotoxic and mutagenic which might cause hereditary diseases that can be transmitted to the future generation [3]. Moreover, this will also provoke the increase of the chemical oxygen demand (COD) and biochemical oxygen demand
(BOD) which inhibit and decrease the rate of photosynthesis and plants' growth [4]. In this context, a wide variety of physical, chemical, and biological techniques have been developed and tested in the treatment of these effluents loaded with dyes. Therefore, adsorption remains one of the easy-to-implement technologies, as it is widely used for water treatment [5]. Nowadays, adsorption has been accepted as a suitable removal technology, particularly for developing regions, because of its simple operation, the potential for regeneration. The adsorption process can be described as "the tendency of chemical species existing in a phase to adhere onto a solid" [6]. Technically, in adsorption science, the solid surface providing the adsorption sites is called adsorbent, and substances that are adsorbed at the solid surface are known as adsorbate [6]. The removal of dyes by adsorption on selective adsorbents such as low-cost adsorbents (sugarcane bagasse) as shown in Figure 1 has been synthesized and tested for dye removal. 


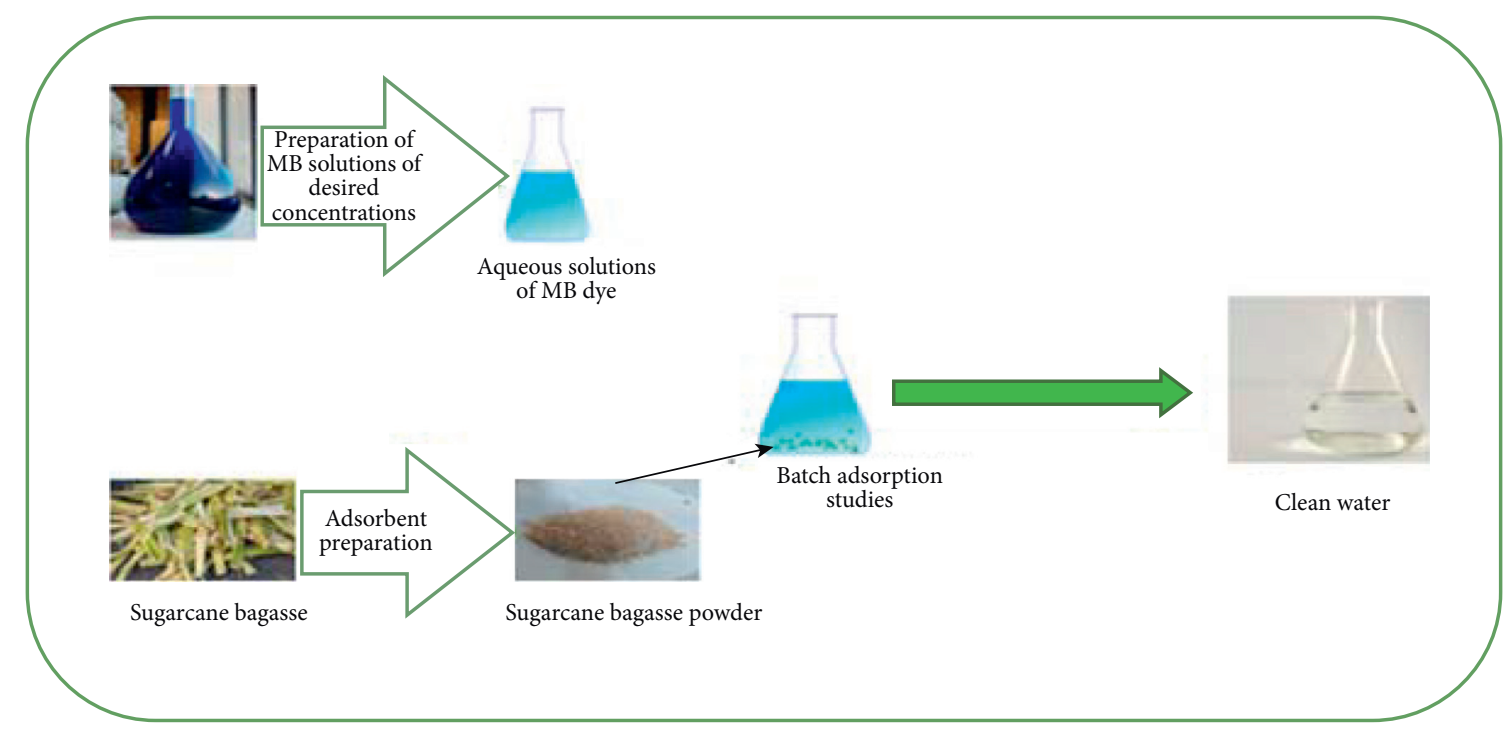

FIgURE 1: Adsorption process of methylene blue by sugarcane bagasse.

From the literature, we can find that the use of activated carbon is considered a good adsorbent due to its high adsorption capacity for organic materials. However, activated carbon is not only expensive but also difficult to regenerate. In this regard, there is a growing interest among researchers in the last few years towards the use of adsorbents that are based and prepared from natural materials with an organic phase such as cellulose, hemicellulose, and lignin contents [7] which are marked by their efficiency and low-cost and their abundance in large quantities in developing countries such as Lgharb region in Morocco. Recently, quite a good number of research articles have been published on the utilization of low-cost adsorbents derived from biomass for wastewater treatment such as banana waste, moringa seed and lemon seed, straws, cotton, and palm fibers; rice (Oryza sativa) and coffee (Coffee Arabica) husk wastes were used [8-10].

Therefore, the present study aims to investigate the $\mathrm{MB}$ dye removal efficiency using cost-effective sustainable solid biomass sugarcane bagasse (SCB) adsorbent materials using batch and the close circuit under various physiochemical process conditions which may be applicable in actual large scale industrial treatment operation.

\section{Materials and Methods}

2.1. Materials. The materials are methylene blue $\mathrm{C}_{16} \mathrm{H}_{18} \mathrm{ClN}_{3} \mathrm{~S}$, sodium chloride $(\mathrm{NaCl}$ purity 99, 8\%), chloride acid ( $\mathrm{HCl}$ purity $37 \%)$, sodium hydroxide $(\mathrm{NaOH}$ purity $98 \%$ ), and sugarcane bagasse (SCB).

2.2. Adsorbate. Methylene blue (MB) is an organic dye that is chosen for this study for its very high degree of purity (99\%). It was used without any prior purification. Its characteristics are grouped in Table 1.

2.3. Adsorbent. Sugarcane bagasse is a natural waste abundantly available in El Ghareb region, Morocco. The sugarcane bagasse was collected from various local "sugarcane juice" venders; then, it was treated as follows: first, it was washed several times to remove the impurities, then dried in the oven at a temperature of $105^{\circ} \mathrm{C}$ for $24 \mathrm{~h}$, and grind and sieved to a particle size equal to $250 \mu \mathrm{m}$.

\section{Characterization of SCB}

This adsorbent's physical and chemical characteristics are viewed to possess high rates of efficiency of pollutants removal [11]. These characteristics are discussed in the following part.

3.1. Textural Characterization. The measurement of the specific surface of pore diameters and pore volume of SCB was obtained by using the nitrogen adsorption-desorption isotherm curve (Micromeritics ASAP 2010) using the Brunauer-Emmett-Teller (BET) method. Morphological analysis was made by scanning electron microscopy (SEM) type (VEGA3 TESCAN) coupled with EDX and quantitative analysis of the elemental composition of SCB was employed using X-ray energy dispersion spectroscopy (EDX).

3.2. Chemical Characterization. The chemical functions of the molecules present in the SCB were analyzed by Fourier Transform Infrared Spectroscopy (FTIR) type (Shimadzu, JASCO 4100). IR spectra were recorded over a wavelength range of 400 and $4000 \mathrm{~cm}^{-1}$. The zero point charge where pHzpc was determined to clarify the net charge was carried by the surface of the SCB.

3.3. Adsorption Procedure. The adsorption tests were conducted in the batch reactor, at ambient temperature; the colored synthetic solution of $\mathrm{MB}$ in the presence of the adsorbent SCB is stirred for an hour; and homogenization of the mixtures was carried out by a Shaker type incubator agitator (Jisico, model J-NSIL-R) with a stirring speed equal to $127 \mathrm{rpm}$. The adsorbate-adsorbent separation was 
TABle 1: Chemical characterization of MB.

\begin{tabular}{ll}
\hline Dye & Methylene blue \\
Structure & Molecular formula \\
Molecular weight $(\mathrm{g} / \mathrm{mol})$ & Maximum wavelength $\lambda \max (\mathrm{nm})$
\end{tabular}

performed using a $0.45 \mu \mathrm{m}$ diameter Wothman-type filtration system, and the supernatant absorbance was measured by a UV-Visible type spectrophotometer (Shimadzu 1601) at a wavelength corresponding to the maximum absorbance of $\operatorname{MB}(\lambda \max =665)$. Then, the residual dye concentration is determined from a calibration curve by Beer Lambert's law.

The adsorption capacity of MB by SCB is calculated by the following formula:

$$
q_{t}=\frac{\left(C_{0}-C_{t}\right) * V}{m}
$$

where $q_{t}\left(\mathrm{mg} \cdot \mathrm{g}^{-1}\right)$ is the amount adsorbed at time $t$ ( $\left.\mathrm{min}\right), C_{0}$ and $C_{t}\left(\mathrm{mg} \cdot \mathrm{L}^{-1}\right)$ are the initial concentration and the concentration at time $t$ in the dye, $V(\mathrm{~L})$ is the volume of the solution, and $m(\mathrm{~g})$ is the amount of the adsorbent in solution.

\section{Results and Discussion}

\subsection{Adsorbent Characterization}

4.1.1. Nitrogen Adsorption-Desorption Isotherm. The nitrogen adsorption-desorption isotherm is obtained at a temperature of $77.35 \mathrm{~K}$ after degassing at $80^{\circ} \mathrm{C}$. The BET $S_{\mathrm{BET}}$ surface area was determined using the Brunauer-Emmett-Teller (BET) equation, the pore volume at saturation $V_{P}$ is the volume of nitrogen corresponding to the highest relative pressure of $P / P_{0}=0.99$, and the pore diameter $D_{P}$ is calculated by the relation $4 \mathrm{Vp} / \mathrm{S}_{\mathrm{BET}}$ [12]. The nitrogen adsorption-desorption isotherm obtained on sugarcane bagasse powder is shown in Figure 2.

According to the classification of isotherms (IUPAC), this curve has a sigmoidal shape, classified as type II, frequently found in fruits with a high sugar content [13], which means that the medium is nonporous or macroporous. The adsorption isotherm obtained shows that the SCB has a nonporous structure; this is confirmed by the textural measurements grouped in Table 2.

4.1.2. Scanning Electron Microscopy (SEM). The SEM images (Figure 3) illustrate the morphological structure of the SCB.

The observations obtained show that sugarcane bagasse has a fibrous structure, each elementary fiber has a compact structure that is aligned in the direction of the fiber axis, and sugarcane bagasse has a smooth and continuous surface $[14,15]$.

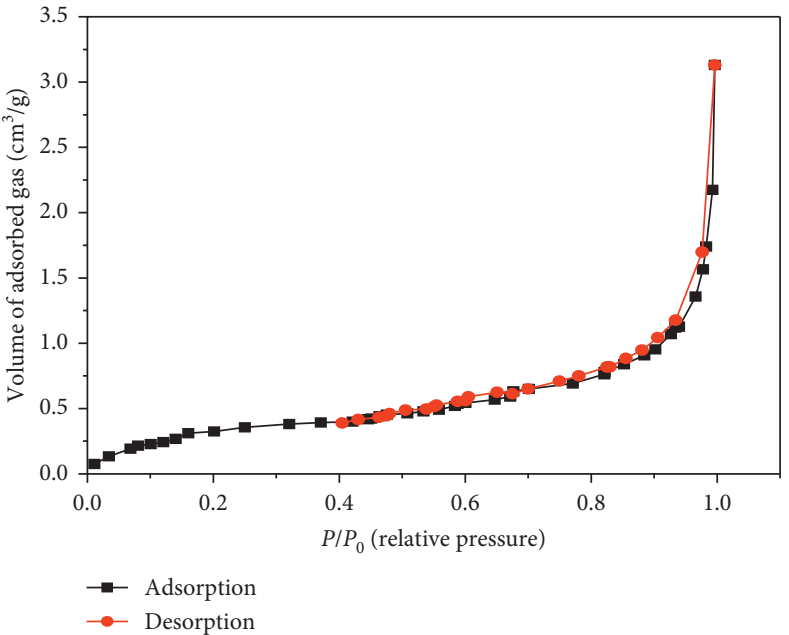

FIgURE 2: Nitrogen adsorption-desorption isotherm of the SCB.

4.1.3. Energy-Dispersive X-Ray Spectroscopy (EDX). The surface elemental analysis of the SCB (Figure 4) indicates the presence of different chemical elements, and those results are grouped in Table 3. Which reveal the important presence of carbon and oxygen with a percentage of $51.10 \%$ and $48.85 \%$, respectively, compared to the other chemical elements $(\mathrm{S}, \ldots)$ which confirms the organic nature of our material [16], and the high oxygen content suggests that the surface of the adsorbent is more acidic.

4.2. Fourier Transform Infrared Spectroscopy (FTIR). The spectrum of sugarcane bagasse recorded by infrared spectroscopy between 400 and $4000 \mathrm{~cm}^{-1}$ is shown in Figure 5 .

Figure 5 shows that the broadband at $3412.92 \mathrm{~cm}^{-1}$ is related to the elongation vibration of the $\mathrm{O}-\mathrm{H}$ bond [17], mainly due to the presence of cellulose molecules [18]. The peak observed at 2922.93 is attributed to the $\mathrm{C}-\mathrm{H}$ elongation and bending vibration of the $\mathrm{CH}_{3}$ methyl group [19]. The peak at $1736 \mathrm{~cm}^{-1}$ is due to the elongation of the carbonyl group of aldehydes and ketones [20]. The 1605 band is due to aromatic skeletal elongation vibrations existing in the lignin structure [21]. The $1053.31 \mathrm{~cm}^{-1}$ band is attributed to stretching vibrations in steric $\mathrm{O}=\mathrm{C}-\mathrm{O}-\mathrm{C}$ compounds due to the existence of hemicellulose $[22,23]$, and the $608.93 \mathrm{~cm}^{-1}$ band corresponds to the bending modes of aromatic compounds [24]. 
TABLE 2: Results of the analyses of the porous network by nitrogen adsorption.

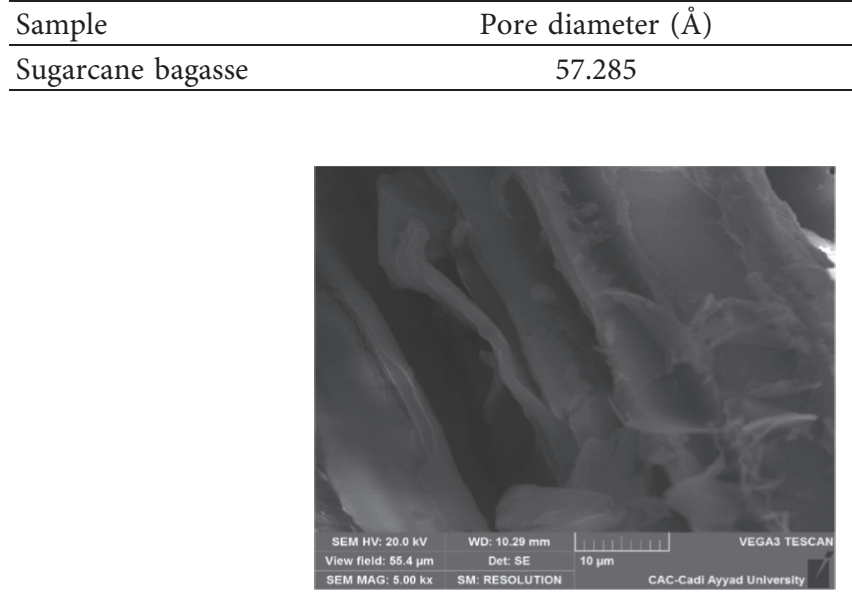

(a)

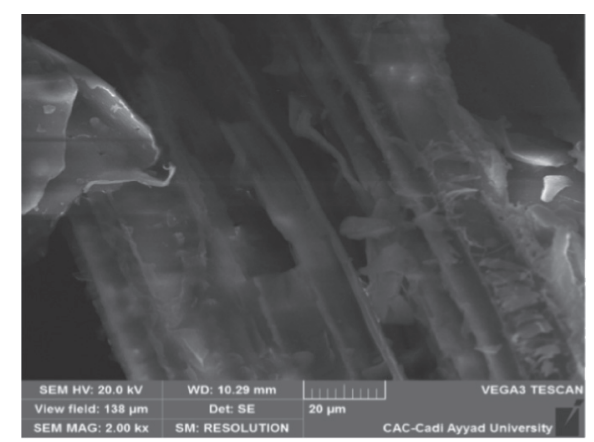

(b)

FIgure 3: Observations of the structure of the SCB at the SEM. (a) Magnification $5.00 \mathrm{kx}$. (b) Magnification $2.00 \mathrm{kx}$.

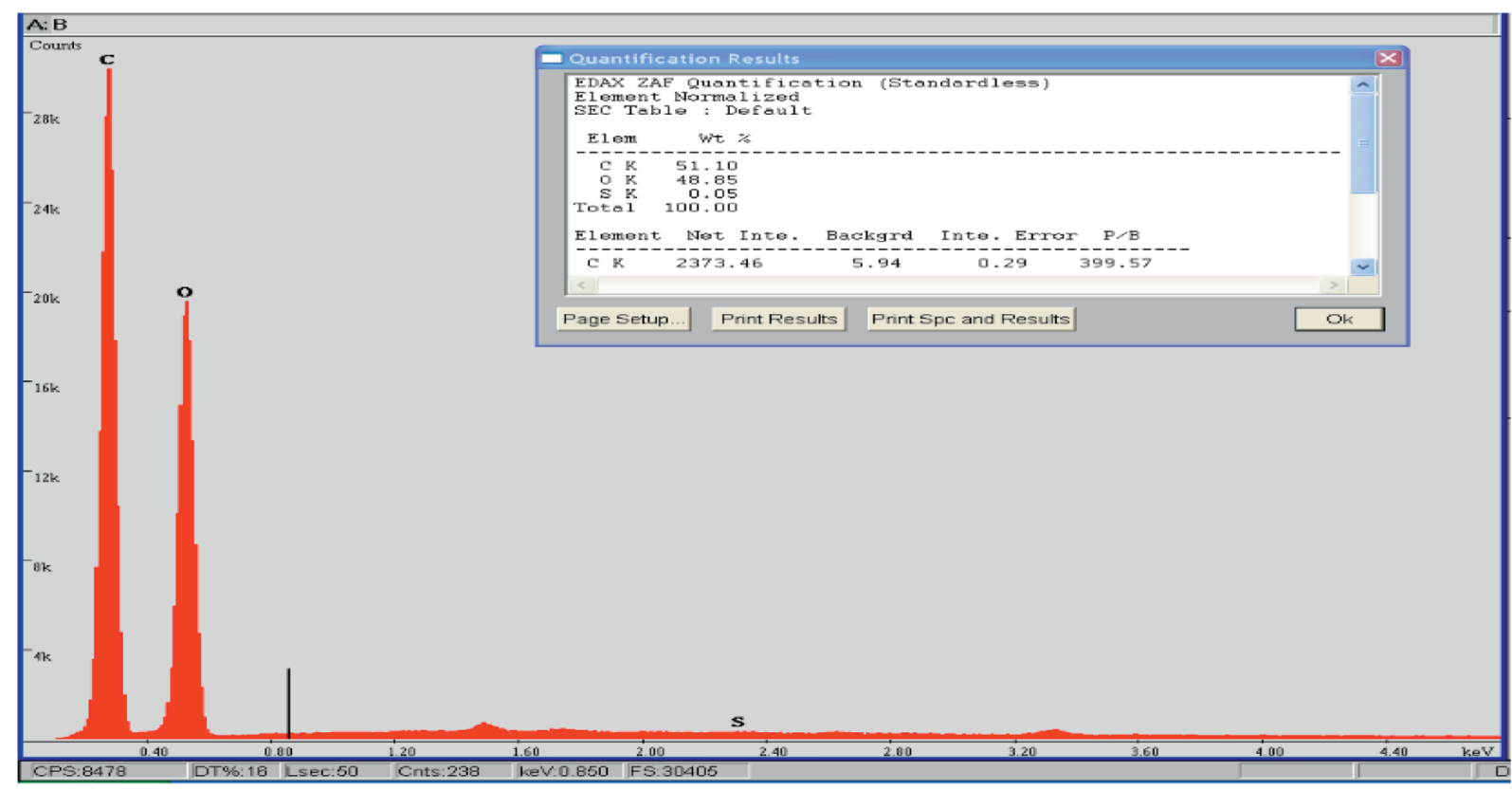

FIGURE 4: EDX spectrum of the SCB.

TABLE 3: Chemical composition of the SCB adsorbent.

\begin{tabular}{lccc}
\hline Element & C (carbon) & O (oxygen) & S (sulfur) \\
\hline Mass percentage & 51.10 & 48.85 & 0.05 \\
\hline
\end{tabular}

4.3. Determination of Zero Point Charge (ZPC). Like many physiochemical variables such as $\mathrm{pH}$, temperature, and $\mathrm{ZPC}$, the latter is considered to be a significant factor that helps in determining the biosorption capacity of the biosorbent and the nature of binding sites $[25,26]$. In this study, this method consists of preparing a series of $20 \mathrm{ml}$ of a $5.10-2 \mathrm{M} \mathrm{NaCl}$ solution, after adjusting the initial $\mathrm{pH}\left(\mathrm{pH}_{i}\right)$ of each to values between 2 and 12, by the addition of $\mathrm{HCl}(0.1 \mathrm{M})$ or $\mathrm{NaOH}$
$(0.1 \mathrm{M})$, a $0.2 \mathrm{~g}$ mass of the SCB is then added to the different solutions. All of this is left to stir at ambient temperature for $48 \mathrm{~h}$ until the final $\mathrm{pH}\left(\mathrm{pH}_{f}\right)$ has stabilized. The intersection of the curve $\Delta \mathrm{pH}\left(\mathrm{pH}_{f}-\mathrm{pH}_{i}\right)$ as a function of $\mathrm{pH}_{i}$ with the $x$ axis determines the ZPC (Figure 6).

The ZPC of the SCB is equal to 4.69 , which expresses that the surface of the SCB is positively charged at a $\mathrm{pH}$ below 4.69 and negatively charged at a $\mathrm{pH}$ above 4.69 . The low ZPC 


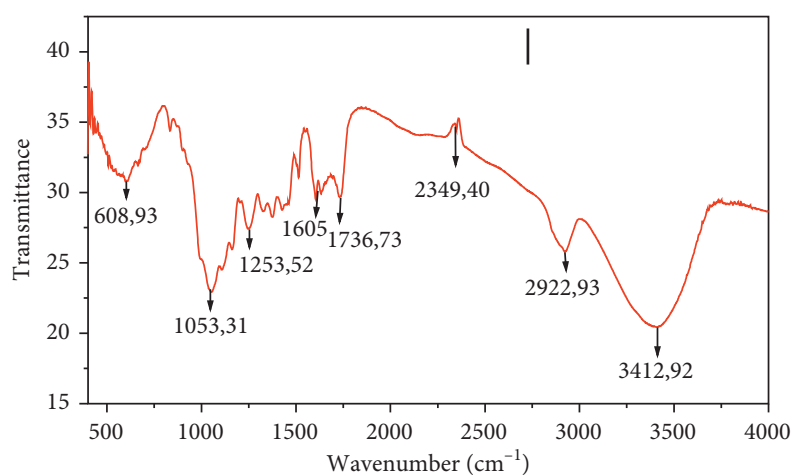

Figure 5: Infrared spectrum of the SCB.

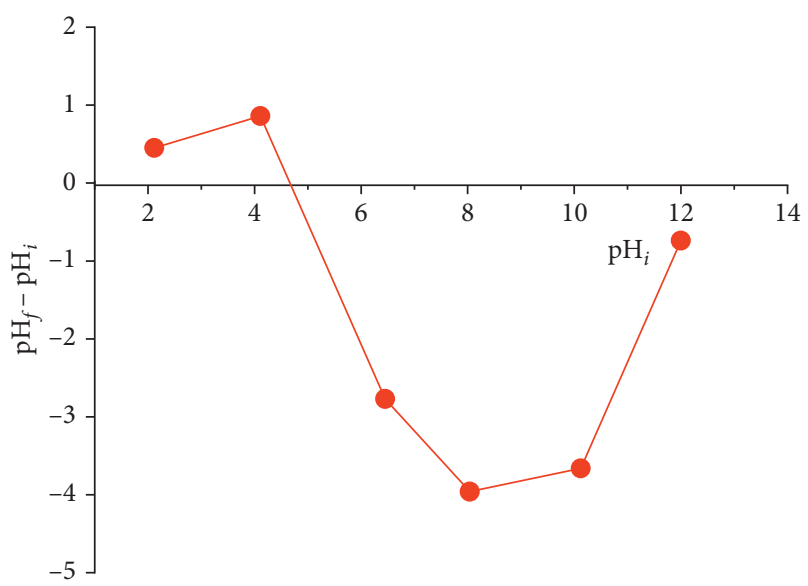

Figure 6: ZPC of the SCB.

value also indicates the acidity of the adsorbent surface, which confirms the results of the elemental chemical composition which shows high oxygen content [26].

\subsection{Effect of Reaction Parameters}

4.4.1. Effects of Adsorbent Amount. Biosorbent dosage has a major role in the dye removal process [26]. This study was conducted by varying the mass of the SCB between 0.05 and $0.5 \mathrm{~g}$, keeping the other parameters constant: an ambient temperature, a solution $\mathrm{pH}$ of 6.4, an initial dye concentration of $25 \mathrm{mg} \cdot \mathrm{L}^{-1}$, and a stirring speed of $127 \mathrm{rpm}$. Figure 7 shows the effect of the adsorbent amount on dye removal.

According to the results obtained, the percentage of dye removal increases with the increase of the adsorbent amount from $80.27 \%$ for $0.05 \mathrm{~g}$ up to $98.49 \%$ for $0.5 \mathrm{~g}$. This phenomenon is due to the increase of the specific surface area and the high availability of the adsorption sites [1]. For the continuation of the studies, we have chosen an amount equal to $0.2 \mathrm{~g}$ with an elimination percentage equal to $95.86 \%$. The chosen amount minimizes the consumption of the amount of the SCB to half compared to $0.5 \mathrm{~g}$ with a percentage of $98.49 \%$ close to that of $0.2 \mathrm{~g}$.

4.4.2. Effect of Contact Time. The experiments were conducted in different contact times, and the variation in the amount of $\mathrm{MB}$ adsorbed by the SCB in the function of contact time (5-120 min) was observed as we set three initial concentrations of dye 5,15 , and $25 \mathrm{mg} \cdot \mathrm{L}^{-1}$ as Figure 8 illustrates.

The results obtained show that the equilibrium time is independent of the initial dye concentration and that the amount of dye fixed on the adsorbent increases with the contact time. Figure 8 reveals the existence of two phases during the adsorption of the MB by the SCB: the first one is the fastest taking 5 minutes, which can be explained by the existence of a high affinity between the cations of the dye and the adsorbent [17], and the second is a slow phase where equilibrium is gradually reached after 20 minutes. This may be due to the saturation of the active sites in the support [27]. The contact time was set at $60 \mathrm{~min}$ for further studies.

4.4.3. Effect of the Initial Dye Concentration. The effect of the initial concentration of $\mathrm{MB}$ on its retention rate by the $\mathrm{SCB}$ was studied at different initial concentrations, ranging from 5 to $100 \mathrm{mg} \cdot \mathrm{L}^{-1}$, and a constant mass of the SCB of $0.2 \mathrm{~g}$ at ambient temperature for 60 minutes (Figure 9).

Figure 9 shows that the percentage of MB removal increases for low concentrations, up to a maximum obtained at $97 \%$ for a concentration of $25 \mathrm{mg} \cdot \mathrm{L}^{-1}$. This can be explained by the availability of active sites which are much higher than the amount of dye introduced. However, at high concentrations, the percentage decreases from $97 \%$ to $56 \%$ due to a lack of available active sites.

4.4.4. Effect of $p H$. The solution $\mathrm{pH}$ plays a significant role in the sorption process as it can affect the surface charge of the adsorbent and the molecular state of the dye molecule. In other words, it interrupts both the solution's chemistry of dyes and functional groups of the adsorbents. Meanwhile, it seems that the adsorption capacity of the dye depends on the $\mathrm{pH}$ of the solution $[25,28]$. The variation of biosorption capacity of SCB for the removal of MB dye was studied in the $\mathrm{pH}$ range of 2 to 12 by adding $\mathrm{HCl}$ (chloride acid) purity $37 \%$ $(0.1 \mathrm{M})$ or $\mathrm{NaOH}$ (sodium hydroxide) purity $98 \%(0.1 \mathrm{M})$, keeping other variables constant $(0.2 \mathrm{~g} / 50 \mathrm{ml}$ biosorbent dose, $25^{\circ} \mathrm{C}$ temperature, $127 \mathrm{rpm}$, and $60 \mathrm{~min}$ contact time). Figure 10 shows the effect of $\mathrm{pH}$ solution on dye removal.

The results indicate that the basic $\mathrm{pH}$ was favorable for the removal of $\mathrm{MB}$. The optimum $\mathrm{pH}$ for maximum dye removal of SCB was found to be 10 , $($ dye removal $=99.30 \%)$.

4.4.5. Effect of Ionic Strength. Wastewater contains various elements such as salts, organic, and metal ions. The presence of those ions is the reason for a high ionic strength which affects the performance of the adsorption process significantly [29]. The study of the influence of this parameter on the adsorption phenomenon is carried out by adding variable amounts of $\mathrm{NaCl}$ (sodium chloride, purity 99.8\%) of concentration ranging from 0 to $0.1 \mathrm{M}$ to solutions of the dye of initial concentration of $25 \mathrm{mg} \cdot \mathrm{L}^{-1}$ and a mass of $0.2 \mathrm{~g}$ of the adsorbent. The influence of the initial concentration of $\mathrm{NaCl}$ on the rate of removal of $\mathrm{MB}$ by SCB is shown in Figure 11. 


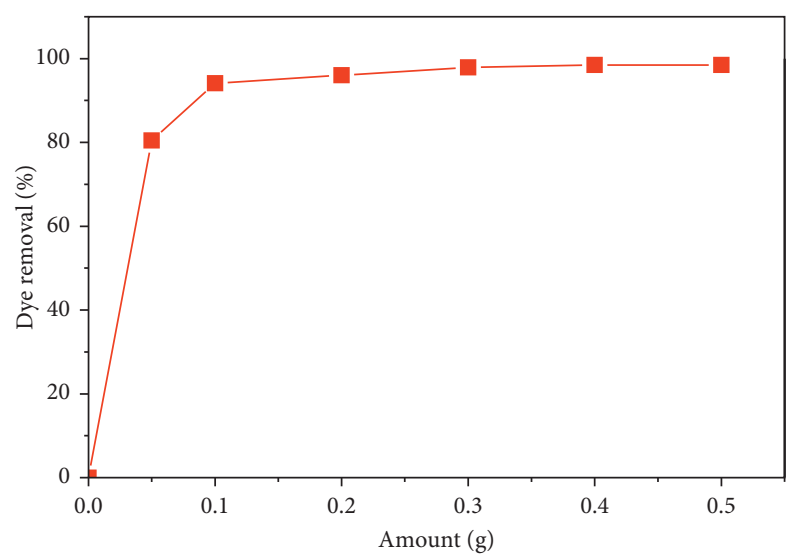

Figure 7: Effect of adsorbent amount on dye removal.

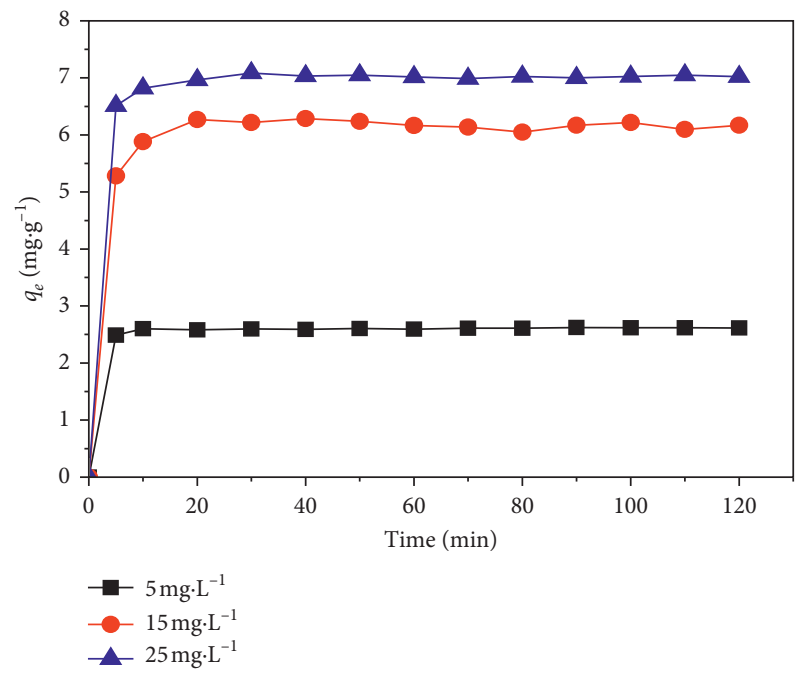

Figure 8: Effect of contact time on the adsorption capacity of MB.

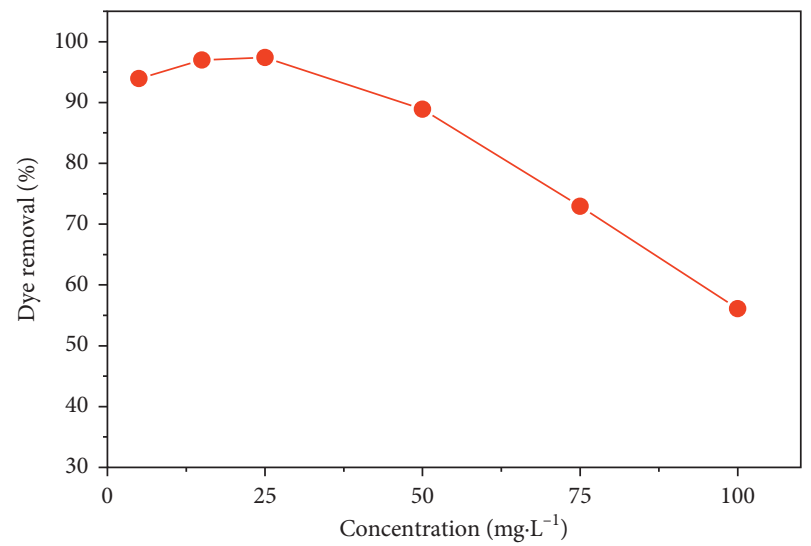

Figure 9: Percentage removal of $\mathrm{MB}$ variation with initial dye concentration by SCB.

According to these results, we notice a great decrease in the rate of elimination of the dye with the increase of the $\mathrm{NaCl}$ concentration from $93.63 \%$ to $77.71 \%$. Above a concentration of $0.04 \mathrm{M} \mathrm{NaCl}$, there is always a decrease but at a very low rate. This phenomenon can be attributed to the fact that $\mathrm{Na}+$ ions accumulate in greater numbers next to the surface and thus screen the fixation sites [30].

4.4.6. Effect of Temperature. The influence of the temperature on the adsorption phenomenon was carried out by adding $0.2 \mathrm{~g} / 50 \mathrm{ml}$ of SCB to a solution of $\mathrm{MB}$ at a concentration of $25 \mathrm{mg} / \mathrm{L}$, at a temperature varying between 15 and $75^{\circ} \mathrm{C}$ (Figure 12).

Figure 11 shows that the $\mathrm{MB}$ removal rate on the SCB decreases from $98.75 \%$ to $89.22 \%$ with increasing temperature from 15 to $75^{\circ} \mathrm{C}$. This decrease can be explained by the destruction of the adsorption sites [31], which means that the increase in temperature adversely affects the adsorption mechanism, so the reaction is exothermic in nature.

4.5. Kinetics Study. MB adsorption kinetics data from the SCB are modeled by three models: pseudo-first-order, pseudo-second-order, and intraparticle diffusion.

The pseudo-first-order kinetic model, evaluated by the Lagergren relation [32], is described by the following equation:

$$
\frac{\mathrm{d} q_{t}}{\mathrm{~d} t}=K_{1}\left(q_{e}-q_{t}\right)
$$

After the integration for the boundary conditions $q_{t}=0$ to $t=0$ and $q_{t}=q_{t}$ to $t=t$, the equation becomes

$$
\ln \left(q_{e}-q_{t}\right)=\ln q_{e}-K_{1} t
$$

The quantity adsorbed at equilibrium $q_{e}$ and the velocity constant $k_{1}$ are obtained from the intercept and the slope of the curve $\ln \left(q_{e}-q_{t}\right)$ versus time $t$, respectively.

The application of Blanchard's model allows us to define the pseudo-second-order of the reaction in a sorption process [33]:

$$
\frac{\mathrm{d} q_{t}}{\mathrm{~d}_{t}}=K_{2}\left(q_{e}-q_{t}\right)^{2} .
$$

The integration of the equation for the boundary conditions $q_{t}=0$ at $t=0$ and $q_{t}=q_{t}$ at $t=t$ gives 


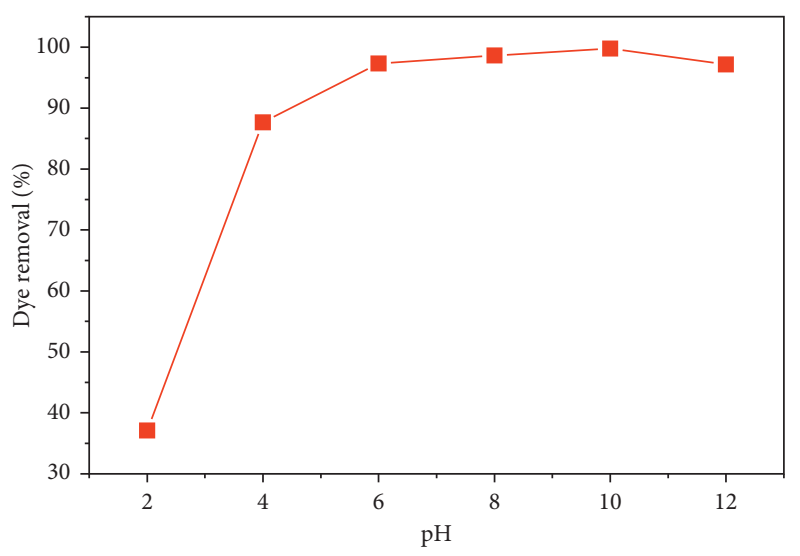

FIgURE 10: Effect of $\mathrm{pH}$ solution on dye removal.

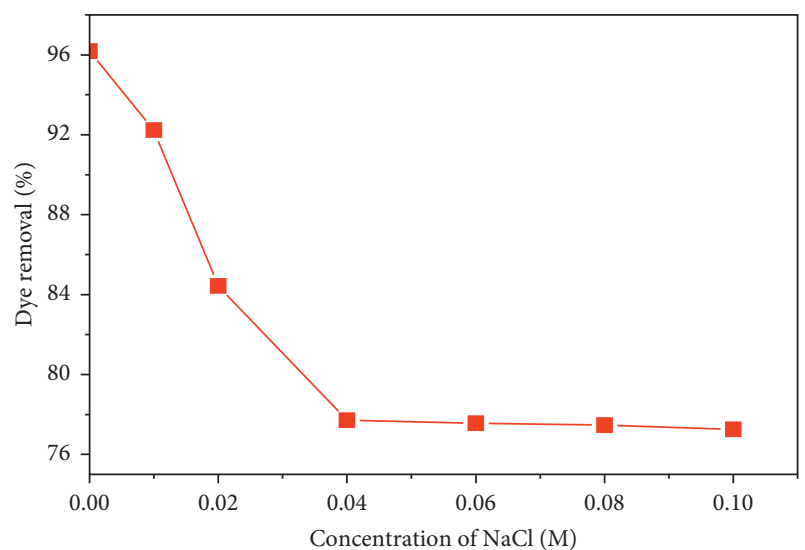

FIGURE 11: Effect of concentration of $\mathrm{NaCl}$ on the removal dye.

$$
\frac{t}{q_{t}}=\frac{1}{K_{2} \times q_{e}^{2}}+\frac{t}{q_{e}} .
$$

The quantity adsorbed at equilibrium $q_{e}$ and the velocity constant $K_{2}$ are determined, respectively, from the slope and the intercept at the origin of the $t / q_{t}$ curve as a function of time $t$.

The intraparticle diffusion (internal transport) is also used to identify the diffusion mechanism. It is presented by the following equation:

$$
q_{t}=K_{i d} \cdot t^{1 / 2}+C
$$

By tracing $q_{t}$ as a function of $t^{1 / 2}$, the constants $K_{i d}$ and $C$ are deduced from the slope and intercept, respectively.

The best model that describes adsorption kinetics is the one with the highest $R^{2}$ linear regression coefficient.

Figure 13 presents the $t / q_{t}$ curve in the function of time $t$ at different initial MB concentrations of the pseudo-secondorder model for $\mathrm{MB}$ adsorption by the SCB and shows improved linearity.

Table 4 summarizes the results of the three models of $\mathrm{MB}$ adsorption kinetics by the SCB. According to this table, the adsorption kinetics is described perfectly with the pseudosecond-order model and the intraparticle diffusion model, with a correlation coefficient which is equal to 1 for the

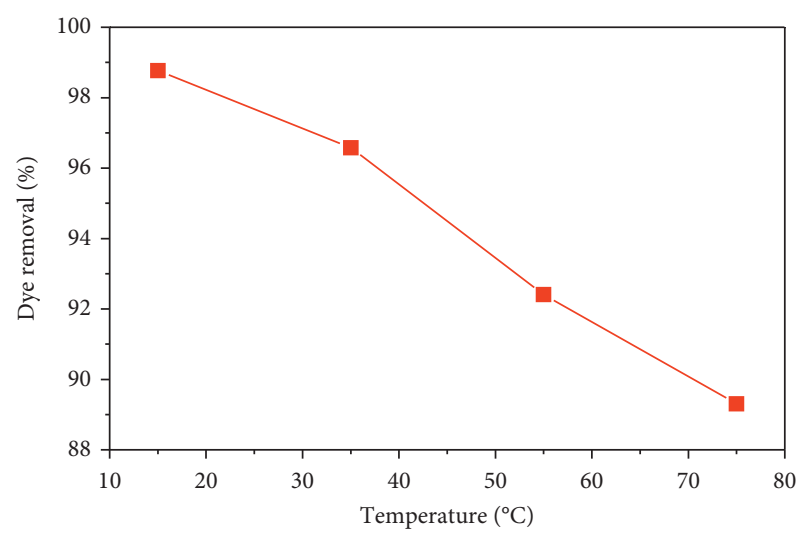

FIgURE 12: Effect of temperature on MB adsorption by the SCB.

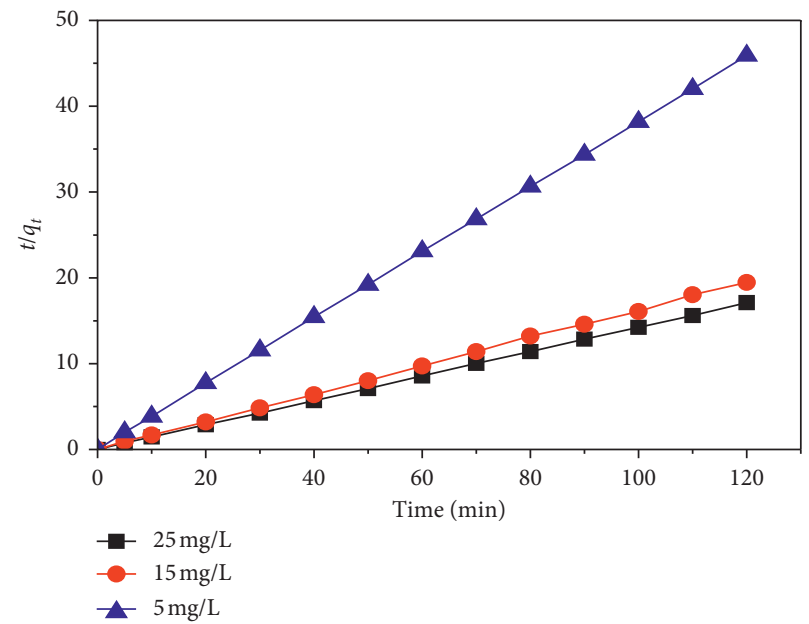

Figure 13: Pseudo-second-order model of adsorption kinetics.

pseudo-second-order kinetic model and 0.96 for the intraparticle diffusion model; the calculated value of the adsorbed quantity at the equilibrium $q_{e, \text { cal }}$ is very close to the experimental value $q_{e \text { exp. }}$. On the other hand, the pseudofirst-order model represents a poor correlation. The velocity constant $K_{2}$ shows that the retention of MB by the SCB is quite fast [27].

4.6. Adsorption Isotherms. Some of the important roles of the adsorption isotherms are that they allow the description of how the adsorbate interacts with the adsorbent, illustrate the type of accumulation of adsorbate on the adsorbent, and analyze the adsorption equilibrium [34]. Experimental data for the MB adsorption isotherms in the SCB were modeled using two models: the Langmuir model and the Freundlich model illustrated below.

4.7. Langmuir Model. Langmuir's model supposes that the adsorption comes from the monolayer coverage of the adsorbate on a homogeneous surface; that is, once a dye molecule takes up at a site, no further adsorption can take place at that site [35], and it is illustrated that 
TABLE 4: Kinetic parameters related to the adsorption of MB on the SCB.

\begin{tabular}{|c|c|c|c|c|}
\hline & $\begin{array}{c}\text { Dye concentration }\left(\mathrm{mg} \cdot \mathrm{L}^{-1}\right) \\
q_{e, \exp }\left(\mathrm{mg}^{-1} \mathrm{~g}^{-1}\right)\end{array}$ & $\begin{array}{c}5 \\
2.621\end{array}$ & $\begin{array}{c}15 \\
6.285\end{array}$ & $\begin{array}{c}25 \\
7.047\end{array}$ \\
\hline \multirow{3}{*}{ Pseudo-first-order kinetic model } & $k_{1}\left(\min ^{-1}\right)$ & 2.1591 & 1.4277 & 1.1817 \\
\hline & $q_{e, \mathrm{cal}}\left(\mathrm{mg} \cdot \mathrm{g}^{-1}\right)$ & 0.968 & 0.991 & 0.9814 \\
\hline & $R^{2}$ & 0.66 & 0.092 & 0.55 \\
\hline \multirow{3}{*}{ Pseudo-second-order kinetic model } & $k_{2}\left(\mathrm{~g} \cdot \mathrm{mg}^{-1} \cdot \mathrm{min}^{-1}\right)$ & 2.329 & 10.156 & 0.991 \\
\hline & $q_{e, \mathrm{cal}}\left(\mathrm{mg} \cdot \mathrm{g}^{-1}\right)$ & 2.621 & 6.153 & 7.032 \\
\hline & $R^{2}$ & 1 & 0.997 & 1 \\
\hline \multirow{6}{*}{ Intraparticle diffusion model } & $K_{i d 1}\left(\mathrm{~g} \cdot \mathrm{mg}^{-1} \cdot \min ^{-1 / 2}\right)$ & 0.8769 & 1.9524 & 2.2958 \\
\hline & $C\left(\mathrm{mg} \cdot \mathrm{g}^{-1}\right)$ & 0.12 & 0.2071 & 0.3122 \\
\hline & $R^{2}$ & 0.94 & 0.96 & 0.93 \\
\hline & $K_{i d 2}\left(\mathrm{~g} \cdot \mathrm{mg}^{-1} \cdot \min ^{-1 / 2}\right)$ & 0.0061 & 0.1168 & 0.1142 \\
\hline & $C\left(\mathrm{mg} \cdot \mathrm{g}^{-1}\right)$ & 2.5538 & 5.5959 & 6.4559 \\
\hline & $R^{2}$ & 0.76 & 0.69 & 0.99 \\
\hline
\end{tabular}

$$
q_{e}=\frac{K_{e} q_{m} C_{e}}{1+K_{L} C_{e}} .
$$

The linear transform of this model has the following equation [36]:

$$
\frac{C_{e}}{q_{e}}=\frac{1}{q_{m} \times K_{L}}+\frac{C_{e}}{q_{m}} .
$$

With $q_{e}$ and $q_{m}\left(\mathrm{mg}^{-1} \mathrm{~g}^{-1}\right)$ being the amount adsorbed at equilibrium and the maximum amount adsorbed at saturation of the monolayer, $C_{e}\left(\mathrm{mg} \cdot \mathrm{L}^{-1}\right)$ is the equilibrium concentration and $K_{L}\left(\mathrm{~L} \cdot \mathrm{mg}^{-1}\right)$ is the Langmuir constant.

By tracing $C_{e} / q_{e}$ according to $C_{e}$, the Langmuir model is checked if a straight line of slope $1 / q_{m}$ and ordinate at the origin $1 / q_{m} K_{L}$ is obtained.

We can check whether adsorption is favorable or not by the equilibrium parameter $R_{L}$ given as

$$
R_{L}=\frac{1}{1+K_{L} C_{0}}
$$

The adsorption is irreversible $\left(R_{L}=0\right)$, favorable $\left(0<R_{L}<1\right)$, linear $\left(R_{L}=1\right)$, and unfavorable $\left(R_{L}>1\right)$ [37].

4.8. Freundlich Model. Freundlich's model is based on an empirical equation used to model adsorption isotherms on energetically heterogeneous surfaces [38]. It is expressed by the following relationship [39]:

$$
q_{e}=K_{F} C_{e}^{1 / n}
$$

where $q_{e}\left(\mathrm{mg} \cdot \mathrm{g}^{-1}\right)$ is the equilibrium amount adsorbed, $K_{F}$ and $n$ are Freundlich's constants, and $C_{e}\left(\mathrm{mg} \cdot \mathrm{L}^{-1}\right)$ is the equilibrium concentration of the solute.

The logarithmic model of this relationship makes it possible to verify its linear transformation [36]:

$$
\ln q_{e}=\frac{1}{n} \ln C_{e}+\ln K_{F} .
$$

The values of $K_{F}$ and $n$ are determined experimentally by drawing $\ln q_{e}$ according to $\ln C_{e}$.
The isotherms of $\mathrm{MB}$ adsorption by the $\mathrm{SCB}$ at $25^{\circ} \mathrm{C}$ are presented according to the Langmuir model (Figure 14) and the Freundlich model (Figure 15).

Table 5 presents the values of the adsorption equilibrium parameters according to the Langmuir and Freundlich model.

According to these results, the correlation coefficient of the Langmuir model is equal to 0.98 , as it is close to the Freundlich correlation coefficient of 0.97 . This means that the process of MB adsorption by SCB is perfectly described by both Langmuir and Freundlich models and the separation factor $R_{L}<1$ indicates that the adsorption is favorable.

4.9. Thermodynamic Study. Thermodynamic parameters such as enthalpy $\Delta H^{\circ}$, entropy $\Delta S^{\circ}$, and free enthalpy $\Delta G^{\circ}$ were calculated at different temperatures of $15,35,55$, and $75^{\circ} \mathrm{C}$ to describe the reaction of $\mathrm{MB}$ adsorption by the SCB from the following equations [40]:

$$
\begin{aligned}
\operatorname{Ln} K_{d} & =\frac{\Delta S^{\circ}}{R}-\frac{\Delta H^{0}}{R T}, \\
\Delta G^{0} & =\Delta H^{0}-T \Delta S^{0} .
\end{aligned}
$$

$K_{d}=q_{e} / C_{e}$ is the distribution coefficient; $q_{e}\left(\mathrm{mg} \cdot \mathrm{g}^{-1}\right)$ is the amount adsorbed at equilibrium; $R$ is the perfect gas constant and $T(\mathrm{~K})$ is the temperature of the solution; and $C_{e}$ $\left(\mathrm{mg} \cdot \mathrm{L}^{-1}\right)$ is the equilibrium concentration.

The thermodynamic parameters play a significant role as they provide information about the spontaneity and endoor exothermicity of the adsorption process and the increment or decrease of randomness at the solid-liquid interface [41].

The plot of $\ln K_{d}$ as a function of $1 / T$ (Figure 16) gives a straight line of slope- $\Delta H^{\circ} / R$ and an intercept at the origin $\Delta S^{\circ} / \mathrm{R}$. The results obtained are grouped in Table 6 .

These results show that the adsorption process of $\mathrm{MB}$ on the SCB is exothermic in nature and can be qualified as physical adsorption since the value of $\Delta H^{\circ}$ is negative and greater than $-40 \mathrm{~kJ} \cdot \mathrm{mol}^{-1}$; the negative value of $\Delta S^{\circ}$ indicates that the molecules of the dye are more organized at the solid/liquid 


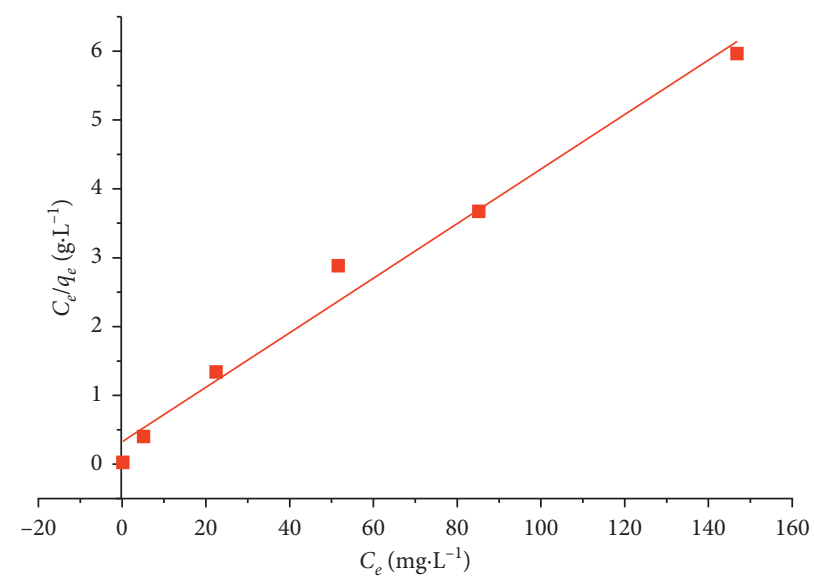

FIgURE 14: Langmuir model for MB adsorption by SCB at $25^{\circ} \mathrm{C}$.

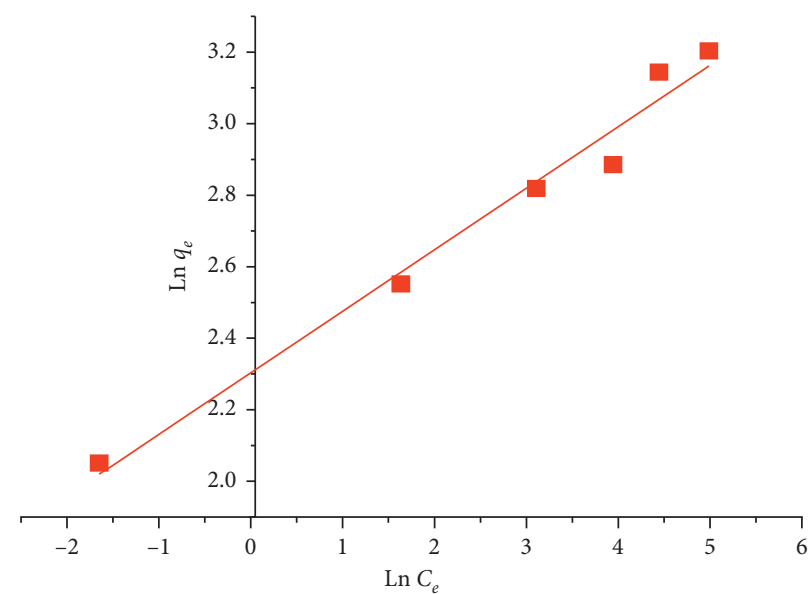

FIgURE 15: Freundlich model for MB adsorption by the SCB at $25^{\circ} \mathrm{C}$.

TABLE 5: Adsorption parameters of the MB on the SCB according to the Langmuir and Freundlich models.

\begin{tabular}{lcc}
\hline & Parameters & Values \\
\hline & $K_{L}\left(\mathrm{~L} \cdot \mathrm{mg}^{-1}\right)$ & 0.1225 \\
Langmuir model & $q_{\max }\left(\mathrm{mg} \cdot \mathrm{g}^{-1}\right)$ & 49.261 \\
& $R_{L}$ & 0.246 \\
& $R^{2}$ & 0.98 \\
\hline & $K_{F}$ & 10.0071 \\
Freundlich model & $1 / n$ & 0.172 \\
& $R^{2}$ & 0.97 \\
\hline
\end{tabular}




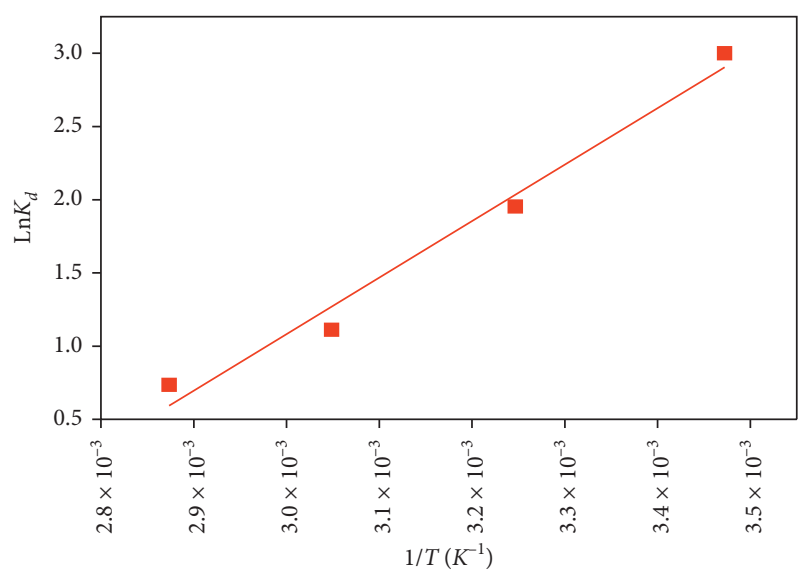

FIgURE 16: Modelling of the thermodynamic study.

TABLE 6: Thermodynamic parameters related to the adsorption of the MB dye on the SCB.

\begin{tabular}{lcccc}
\hline \multirow{2}{*}{ Thermodynamic parameters } & \multicolumn{4}{c}{ Temperature $\left({ }^{\circ} \mathrm{K}\right)$} \\
& 288 & 308 & 328 & 348 \\
\hline$\Delta G^{\circ}\left(\mathrm{kJ} \cdot \mathrm{mol}^{-1}\right)$ & -6.87 & -5.19 & -3.51 & -1.83 \\
$\Delta S^{\circ}\left(\mathrm{kJ} \cdot \mathrm{mol}^{-1} \cdot \mathrm{K}^{-1}\right)$ & \multicolumn{4}{c}{-0.084} \\
$\Delta H^{\circ}\left(\mathrm{kJ} \cdot \mathrm{mol}^{-1}\right)$ & \multicolumn{4}{c}{-31.062} \\
\hline
\end{tabular}

interface than in solution, hence a decrease in molecular disorder. Negative values of $\Delta G^{\circ}$ indicate that adsorption is spontaneous and the increase in these values as the temperature increases from 15 to $75^{\circ} \mathrm{C}$ shows that the feasibility of adsorption decreases at elevated temperatures [42].

\section{Conclusion}

The adsorption process of MB on the SCB was the aim of this study. The results obtained show that the removal rate of $\mathrm{MB}$ increases from $80.27 \%$ to $98.49 \%$ with the increase of the mass of adsorbent from $0.05 \mathrm{~g}$ to $0.5 \mathrm{~g}$ due to the increase in specific surface area. The maximum removal of dye was observed at $\mathrm{pH} 10$ and the biosorption process has reached equilibrium at $60 \mathrm{~min}$. The contact time effect indicated that the equilibrium time is independent of the initial $\mathrm{MB}$ concentration, adsorption is very fast after $5 \mathrm{~min}$, and equilibrium time is reached at $20 \mathrm{~min}$. On the other hand, the rate of elimination decreases with increasing temperature. Therefore, an exothermic reaction occurs.

The kinetic and isothermal studies of the adsorption mechanism are perfectly described by pseudo-secondorder kinetics and both Langmuir and Freundlich models as they perfectly present the adsorption of $\mathrm{MB}$ on the SCB. Finally, the thermodynamic studies have shown that the adsorption of MB by the SCB is exothermic, feasible, and spontaneous.

To conclude, SCB is found to be a good biosorbent for $\mathrm{MB}$ removal which makes it a great alternative for wastewater and dye effluents treatment, especially today, as we need to protect the environment using environment-friendly processes like this.

\section{Data Availability}

The datasets generated and/or analyzed during the current study are available from the corresponding author on reasonable request.

\section{Conflicts of Interest}

The authors declare that they have no conflicts of interest.

\section{References}

[1] A. Ahmad, M. Rafatullah, O. Sulaiman, M. H. Ibrahim, and R. Hashim, "Scavenging behaviour of meranti sawdust in the removal of methylene blue from aqueous solution," Journal of Hazardous Materials, vol. 170, no. 1, pp. 357-365, 2009.

[2] H. B. Mansour, O. Boughzala, d. Dridi, D. Barillier, L. ChekirGhedira, and R. Mosrati, "Les colorants textiles sources de contamination de l'eau: CRIBLAGE de la toxicité et des méthodes de traitement," Revue des Sciences de L'eau, vol. 24, no. 3, pp. 209-238, 2011.

[3] M. Iqbal, "Vicia faba bioassay for environmental toxicity monitoring: a review," Chemosphere, vol. 144, pp. 785-802, 2016.

[4] D. Dahiya and P. S. Nigam, "Waste management by biological approach employing natural substrates and microbial agents for the remediation of dyes' wastewater," Applied Sciences, vol. 10, no. 8, p. 2958, 2020.

[5] N. Fayoud, S. A. Younssi, S. Tahiri, and A. Albizane, "Kinetic and thermodynamic study of the adsorption of methylene blue on wood ashes," Journal of Materials and Environmental Science, vol. 11, pp. 3295-3306, 2015.

[6] M. A. Alaei Shahmirzadi, S. S. Hosseini, J. Luo, and I. Ortiz, "Significance, evolution and recent advances in adsorption technology, materials and processes for desalination, water softening and salt removal," Journal of Environmental Management, vol. 215, pp. 324-344, 2018.

[7] S. V. Vassilev, D. Baxter, L. K. Andersen, C. G. Vassileva, and T. J. Morgan, "An overview of the organic and inorganic phase composition of biomass," Fuel, vol. 94, pp. 1-33, 2012.

[8] S. B. Patil, P. Sabale, and S. A. Patil, "Experimental study on dye removal of textile wastewater by using natural adsorbent," Resincap Journal of Science \& Engineering, vol. 3, pp. 526-533, 2019.

[9] O. Abdelwahab, S. M. Nasr, and W. M. Thabet, "Palm fibers and modified palm fibers adsorbents for different oils," Alexandria Engineering Journal, vol. 56, no. 4, pp. 749-755, 2017.

[10] T. Ahmad and M. Danish, "Prospects of banana waste utilization in wastewater treatment: a review," Journal of Environmental Management, vol. 206, pp. 330-348, 2018.

[11] M. Wakkel, B. Khiari, and F. Zagrouba, "Textile wastewater treatment by agro-industrial waste: equilibrium modelling, thermodynamics and mass transfer mechanisms of cationic dyes adsorption onto low-cost lignocellulosic adsorbent," Journal of the Taiwan Institute of Chemical Engineers, vol. 96, pp. 439-452, 2019.

[12] C. Balogoun, M. Bawa, S. Osseni, and M. Aina, "Préparation des charbons actifs par voie chimique à l'acide phosphorique à base de coque de noix de coco," International Journal of Biological and Chemical Sciences, vol. 9, no. 1, p. 563, 2015. 
[13] A. Ferradji and A. Malek, "Isothermes d'adsorption des abricots secs à $25 \mathrm{C}$ et $45 \mathrm{C}$," Renewable \& Sustainable Energy Reviews, vol. 8, p. 39, 2005.

[14] A. Mandal and D. Chakrabarty, "Isolation of nanocellulose from waste sugarcane bagasse (SCB) and its characterization," Carbohydrate Polymers, vol. 86, no. 3, pp. 1291-1299, 2011.

[15] G. J. M. Rocha, A. R. Gonçalves, B. R. Oliveira, E. G. Olivares, and C. E. V. Rossell, "Steam explosion pretreatment reproduction and alkaline delignification reactions performed on a pilot scale with sugarcane bagasse for bioethanol production," Industrial Crops and Products, vol. 35, no. 1, pp. 274-279, 2012.

[16] S. Boumchita, A. Lahrichi, Y. Benjelloun, S. Lairini, V. Nenov, and F. Zerrouq, "Removal of cationic dye from aqueous solution by a food waste: potato peel," Journal of Materials and Environmental Science, vol. 7, no. 1, pp. 73-84, 2016.

[17] F. Mekhalef Benhafsa, S. Kacha, A. Leboukh, and K. D. Belaid, "Étude comparative de l'adsorption du colorant victoria bleu basique à partir de solutions aqueuses sur du carton usagé et de la sciure de bois," Revue des Sciences de L'eau, vol. 31, no. 2, pp. 109-126, 2018.

[18] H. Yang, R. Yan, H. Chen, D. H. Lee, and C. Zheng, "Characteristics of hemicellulose, cellulose and lignin pyrolysis," Fuel, vol. 86, no. 12-13, pp. 1781-1788, 2007.

[19] R. Han, L. Zhang, C. Song, M. Zhang, H. Zhu, and L. Zhang, "Characterization of modified wheat straw, kinetic and equilibrium study about copper ion and methylene blue adsorption in batch mode," Carbohydrate Polymers, vol. 79, no. 4, pp. 1140-1149, 2010.

[20] C. R. Teixeira Tarley and M. A. Zezzi Arruda, "Biosorption of heavy metals using rice milling by-products. Characterisation and application for removal of metals from aqueous effluents," Chemosphere, vol. 54, no. 7, pp. 987-995, 2004.

[21] S. H. Ghaffar and M. Fan, "Structural analysis for lignin characteristics in biomass straw," Biomass and Bioenergy, vol. 57, pp. 264-279, 2013.

[22] S. Naik, V. V. Goud, P. K. Rout, K. Jacobson, and A. K. Dalai, "Characterization of Canadian biomass for alternative renewable biofuel," Renewable Energy, vol. 35, no. 8, pp. 1624-1631, 2010.

[23] B.-L. Xue, J.-L. Wen, F. Xu, and R.-C. Sun, "Structural characterization of hemicelluloses fractionated by graded ethanol precipitation from Pinus yunnanensis," Carbohydrate Research, vol. 352, pp. 159-165, 2012.

[24] U. K. Garg, M. P. Kaur, V. K. Garg, and D. Sud, "Removal of hexavalent chromium from aqueous solution by agricultural waste biomass," Journal of Hazardous Materials, vol. 140, no. 1-2, pp. 60-68, 2007.

[25] A. Kausar, M. Iqbal, A. Javed et al., "Dyes adsorption using clay and modified clay: a review," Journal of Molecular Liquids, vol. 256, pp. 395-407, 2018.

[26] S. Noreen, H. N. Bhatti, M. Iqbal, F. Hussain, and F. M. Sarim, "Chitosan, starch, polyaniline and polypyrrole biocomposite with sugarcane bagasse for the efficient removal of acid black dye," International Journal of Biological Macromolecules, vol. 147, pp. 439-452, 2020.

[27] H. B. Senturk, D. Ozdes, and C. Duran, "Biosorption of rhodamine $6 \mathrm{G}$ from aqueous solutions onto almond shell (Prunus dulcis) as a low cost biosorbent," Desalination, vol. 252, no. 1-3, pp. 81-87, 2010.

[28] Y. Song, J. Tan, G. Wang, and L. Zhou, "Superior amine-rich gel adsorbent from peach gum polysaccharide for highly efficient removal of anionic dyes," Carbohydrate Polymers, vol. 199, pp. 178-185, 2018.
[29] A. K. Kushwaha, N. Gupta, and M. C. Chattopadhyaya, "Removal of cationic methylene blue and malachite green dyes from aqueous solution by waste materials of Daucus carota," Journal of Saudi Chemical Society, vol. 18, no. 3, pp. 200-207, 2014.

[30] Z. Reddad, C. Gérente, Y. Andrès, and P. Le Cloirec, "Valorisation d'un sous-produit de l'industrie sucrière: mise en œuvre dans un procédé de traitement d'eaux usées industrielles," Déchets, Sciences et Techniques, vol. 39, no. 39, 2005.

[31] N. Tazerouti and M. Amrani, "Adsorption du Cr (VI) sur la lignine activée," Revue des Sciences de L'eau, vol. 23, no. 3, pp. 233-245, 2010.

[32] D. Mohan, K. Singh, and V. Singh, "Trivalent chromium removal from wastewater using low cost activated carbon derived from agricultural waste material and activated carbon fabric cloth," Journal of Hazardous Materials, vol. 135, no. 1-3, pp. 280-295, 2006.

[33] T. Chouchane, S. Chouchane, A. Boukarai, A. Balaska, and M. E. Samar, "Elimination du plomb en solution par la sciure de bois," Revue des Énergies Renouvelables, vol. 14, pp. 613626, 2011.

[34] G. Rivard, “Cinétique d'adsorption des contaminants de l'eau blanche sur les fines,” Ph. D. thesis, Université du Québec à Trois-Rivières, Trois-Rivières, Canada, 2011.

[35] Y. Miyah, A. Lahrichi, M. Idrissi, A. Khalil, and F. Zerrouq, "Adsorption of methylene blue dye from aqueous solutions onto walnut shells powder: equilibrium and kinetic studies," Surfaces and Interfaces, vol. 11, pp. 74-81, 2018.

[36] A. B. Karim, B. Mounir, M. Hachkar, M. Bakasse, and A. Yaacoubi, "Élimination du colorant basique "Bleu de Méthylène" en solution aqueuse par l'argile de Safi," Revue Des Sciences De L'Eau, vol. 23, no. 4, pp. 375-388, 2010.

[37] M. T. Yagub, T. K. Sen, S. Afroze, and H. M. Ang, "Dye and its removal from aqueous solution by adsorption: a review," Advances in Colloid and Interface Science, vol. 209, pp. 172184, 2014.

[38] H. M. F. Freundlich, "Over the adsorption in solution," Journal of Physical Chemistry, vol. 57, no. 1906, pp. 385-470, 1906.

[39] J. Avom, J. K. Mbadcam, M. R. L. Matip, and P. Germain, "Adsorption isotherme de l'acide acétique par des charbons d'origine végétale," African Journal of Science and Technology, vol. 2, no. 2, 2001.

[40] Z. Bouberka, S. Kacha, M. Kameche, S. Elmaleh, and Z. Derriche, "Sorption study of an acid dye from an aqueous solutions using modified clays," Journal of Hazardous Materials, vol. 119, no. 1-3, pp. 117-124, 2005.

[41] L. Bulgariu, L. B. Escudero, O. S. Bello et al., "The utilization of leaf-based adsorbents for dyes removal: a review," Journal of Molecular Liquids, vol. 276, pp. 728-747, 2019.

[42] A. Mittal, V. Thakur, J. Mittal, and H. Vardhan, "Process development for the removal of hazardous anionic azo dye congo red from wastewater by using hen feather as potential adsorbent," Desalination and Water Treatment, vol. 52, no. 1-3, pp. 227-237, 2014. 